\begin{tabular}{|c|c|c|}
\hline Silit & $\begin{array}{c}\text { Türkiye Tarımsal Araştırmalar Dergisi } \\
\text { dergipark.org.tr/tutad }\end{array}$ & $\begin{array}{l}\text { Turk J Agric Res } \\
\text { 2020, 7(2): 120-127 } \\
\text { ○ TÜTAD } \\
\text { ISSN: 2148-2306 }\end{array}$ \\
\hline 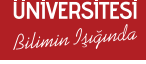 & Research Article & $\begin{array}{l}\text { e-ISSN: } 2528-858 \mathrm{X} \\
\text { doi: } 10.19159 / \text { tutad.585170 }\end{array}$ \\
\hline
\end{tabular}

\title{
Investigation of Salt Stress in Rosemary (Rosmarinus officinalis L.) with the Remote Sensing Technique
}

\author{
Rutkay ATUN ${ }^{1}$, Esra UÇAR ${ }^{2}$, Önder GÜRSOY ${ }^{*}$ \\ ${ }^{1}$ Sivas Cumhuriyet University, Faculty of Engineering, Department of Geomatics, Sivas, TURKEY \\ ${ }^{2}$ Sivas Cumhuriyet University, Sivas Vocational School, Department of Crop and Animal Production, Sivas, TURKEY
}

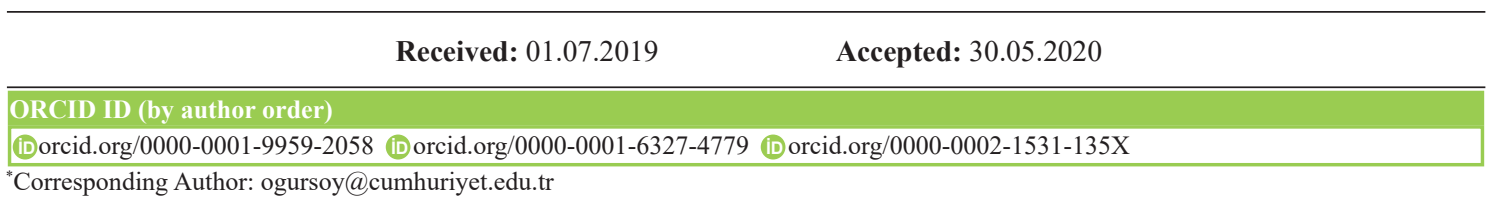

\begin{abstract}
In the present work, the effect of different salt concentrations on growth and quality of rosemary (Rosmarinus officinalis L.) was investigated using ground-based remote sensing techniques under greenhouse conditions in 2018. The experiment was carried out in a randomized complete block design with three replications and lasted 8 weeks in total. Spectroradiometer measurements were performed on the leaves of rosemary plants to monitor changes in spectral signatures due to salt stress. Spectrophotometer and chlorophyll meter measurements were also taken from the leaves of the plants to investigate the reactions to salt stress at the end of $4^{\text {th }}$ and $8^{\text {th }}$ weeks simultaneously with all other measurements. According to the obtained data, there was a significant difference in the chlorophyll, brightness and colour values of the leaves in response to salt stress, and a difference was observed in the reflective values of the plants in the spectral measurements taken at $4^{\text {th }}$ and $8^{\text {th }}$ weeks. The region with the biggest difference between reflectance values was near-infrared among different salt concentrations applied plants. In the $4^{\text {th }}$ week, the most vivid color (intense green) was obtained in the S3 and S4 applications, (19.80 and 19.40, respectively). However, as the stress application time and the applied salt rate increased, small changes in plant color occurred. Besides, it was concluded that salt treatment increased the NDVI (Normalized Difference Vegetation Index) values of the plants.
\end{abstract}

Keywords: Salt stress, spectral measurement, rosemary, chlorophyll measurement

\section{Introduction}

Rosemary (Rosmarinus officinalis L.) is a member of the Lamiaceae family (Olmedo et al., 2013). The rosemary plant has many uses such as stimulating the digestive system, increasing bile secretion and healing wounds. In addition, antifungal, antioxidant and insecticidal effects are other benefits of the plant (K1rp1k, 2005; Lemos et al., 2015). And for these reasons, it is also used in fields such as agriculture, medicine, and pharmaceutical production. The chemical components of the rosemary plant are $20 \%$ a-pinene, $20 \%$ cineol, $18 \%$ camphor, $6 \% \beta$-pinen $5 \%$ borneol, $5 \%$ mirsen, $3 \%$ bornicyl acetate, $2 \%$ terpineol, limonene, terpineol and cariophillen (Simon et al., 1984; Bayrak, 2006).
Salt stress, which is a parameter significantly influencing the production and quality of plants, is an abiotic stress factor that also causes osmotic and ionic stress. These adverse effects may vary depending on the type of salt applied, the intensity and duration of stress, the genotype, and the developmental stage of the plant. While some plants are sensitive to these conditions, others can survive with various physiological and biochemical tolerance mechanisms (Çulha and Çakırlar, 2011). In addition, almost all plants are adversely affected by salt stress. The chlorophyll content and photosynthesis rate of the plants under stress are reduced (Lugassi et al., 2017; Trigueros et al., 2017).

With current developments in technology, usage areas of remote sensing have increased. One 
of these areas is agricultural applications. Remote sensing collects reflectance data without physical contact and provides information quickly and effectively, about the characters in the electromagnetic spectrum of objects, compared to traditional agricultural methods (Özyiğit and Bilgen, 2013; Özyiğit, 2017). The areas of application of remote sensing in agriculture include irrigation, fertilization, detection of chlorophyll content, plant growth monitoring and plant stress (Argyrokastritis et al., 2015; Caturegli et al., 2015; Ramoelo et al., 2015; He et al., 2016; Katsoulas et al., 2016; Birdal et al., 2017; Wang et al., 2017).

In some studies in the literature, multispectral and ground-based remote sensing have been used together to detect the amount of fertilizer in plants and salt stress. In this context, different amounts of fertilization were applied to plants grown in a greenhouse environment. Spectroradiometer measurements were performed on the leaves of each plant after the plants grown, and thus, the effect of different amounts of fertilizer application on the reflectance of the plants was determined. In addition, various indices such as NDVI (Normalized Difference Vegetation Index) and NDRE (Normalized Difference Red Edge Index) were used to calculate the effect of fertilizer in plants and salt stress. Different fertilization amounts and salt stress can be understood with the applied techniques (Tilling et al., 2007).

With the use of thermal cameras and multispectral images obtained by unmanned aerial vehicles, water status and chlorophyll amount of plants can also be determined. It is possible to detect the effect of different fertilization rates applied to plants by using spectral differences of remote sensing images. In this type of study, it has been observed that classification, thermal imaging, and vegetation index techniques yield effective results for the determination of factors such as chlorophyll and mineral composition of plants. (Yousfi et al., 2016; Trigueros et al., 2017; Gürsoy and Atun, 2019).

One of the uses of remote sensing in agriculture is plant growth monitoring, which has become increasingly important due to factors such as climate change, natural hazards, and urbanization. In this context, technologies such as geographical information systems and LIDAR (Laser Imaging Detection and Ranging) contribute to the effective monitoring of plant growth (Cordell et al., 2017; Akram et al., 2019). Soil salinity monitoring is another area of use of remote sensing in agriculture. Soil salinity monitoring can be performed with techniques such as multispectral satellite sensors, hyperspectral data, vegetation, and soil indices. Besides, salt stress tolerance in plants, effects of salinity, and yield productivity under salt stress can also be determined by groundbased and optical remote sensing methods. Remote sensing successfully applied to salt stress and yield related studies. Studies have shown significant correlations between salt stress and yield. The effect of saltwater irrigation on canopy temperature is also reported (Pinter et al., 2003; Allbed and Kumar, 2013; Sytar et al., 2017; Ali et al., 2019).

Thus, it can be seen that there are diverse areas of use of remote sensing in agriculture. It provides great convenience in the implementation of agricultural policies in large agricultural lands, thereby effectively managing sustainable agriculture (Tilling et al., 2007; Meggio et al., 2010; Chemura et al., 2017).

The purpose of this study was to demonstrate the use of ground-based remote sensing in the salt tolerance measurement of the rosemary plant.

\section{Materials and Methods}

\subsection{Application of salt stress to rosemary plants}

This study was conducted in the greenhouses of Sivas Vocational School, Cumhuriyet University in 2018. First, rosemary cuttings (each cutting 10 $\mathrm{cm}$ in length was taken from the same plant) were rooted in the greenhouse and planted in pots in a peat and perlite mix (1:1). When the plants reached $15 \mathrm{~cm}$ in height, salt stress treatment was applied for 8 weeks. The control group labeled S1 had no salt $(0 \mathrm{~g} \mathrm{NaCl})$ and only $100 \mathrm{~mL}^{-1}$ of pure water

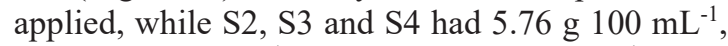

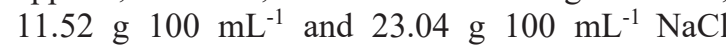
solutions, respectively, with 4 different irrigations. The experiment was conducted in a randomized complete blocks design with three replications (3 plants per replication) and lasted for 60 days.

\subsection{Spectral measurements in plants}

When plants were growing, spectroradiometer measurements were made on the leaves to observe changes in reflectance depending on the stress level. The spectroradiometer measurements were taken using an ASD Field Spec Pro 4 device (Mac Arthur et al., 2007), with a measurement sensitivity of 350-2500 nanometers. White reference (spectralon) measurements were taken before starting the process. The measurements were taken 5 times in reflectance mode for each plant. When the spectroradiometer measurements were finished, the reflectance was analyzed using the ASD ViewSpec Pro software (Hatchell, 1999). 


\subsection{Chlorophyll and color change} measurements in stressed plants

A MC-100 Apogee chlorophyll meter (Parry et al., 2014) was used to measure the chlorophyll concentration on the leaves of the plants. The $\mathrm{K}$ value obtained by the chlorophyll meter is the value that expresses the chlorophyll concentration of plants. A Minolta CR-200 (MINOLTA Camera Co, LTD Ramsey, NJ) spectrophotometer was also used to monitor the color changes on the leaves of the plants. The Minolta CR-200 gives three different $(\mathrm{L}, \mathrm{a}, \mathrm{b})$ numerical values. The $\mathrm{L}$ value expresses brightness in a range of $0-100$, with 0 as black with no reverberation and 100 as white with perfect reverberation (Figure 1).

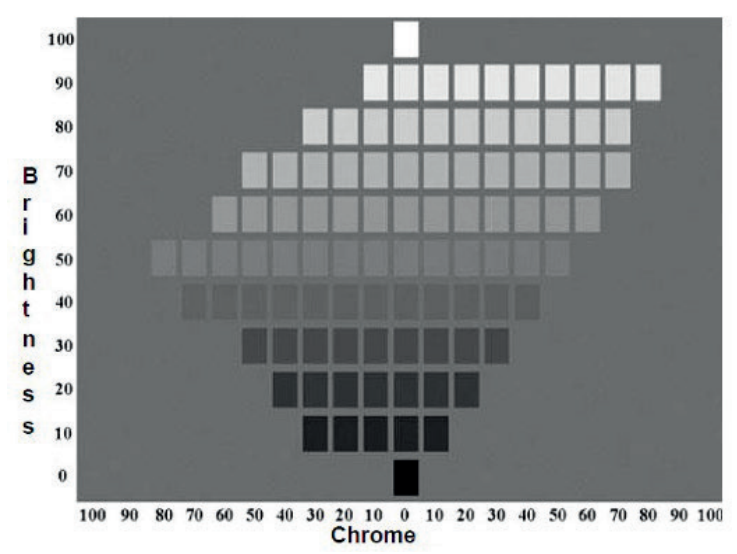

Figure 1. Brightness-chrome diagram

A positive "a" value represents the red color and negative " $a$ " represents the green color; positive " $b$ " values present the yellow color, and negative " $b$ " values represent the blue color. At the point of zero-cut $(\mathrm{a}=0$ and $\mathrm{b}=0)$, it becomes colorless or grey (Figure 2).

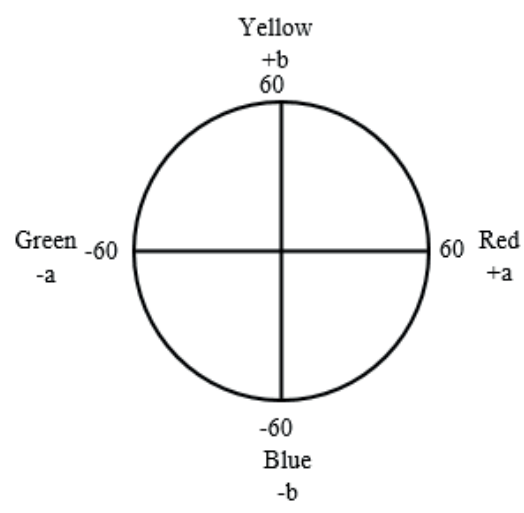

Figure 2. Color diagram

The hue angle value which expresses the angle made by the $\mathrm{X}$-axis from the point where $\mathrm{a}$ and $\mathrm{b}$ values intersect is calculated. The hue angle is $0^{\circ}$ in red, $90^{\circ}$ in yellow, $180^{\circ}$ in green and $270^{\circ}$ in blue. The chroma value indicates the viability of the plant leaf and has a low value in dull colors and high in vivid colors. Chroma (C) and hue angle (h) values were calculated by using Equations 1-2 (McGuire, 1992). The instrument was calibrated with a white standard plate before each measurement.

$$
\begin{aligned}
& C=\sqrt{ }(a)^{2}+(b)^{2} \\
& h^{\circ}=\tan ^{-1}[(a / b)]
\end{aligned}
$$

The $h^{\circ}$ represents values between 0 and 360 . The chroma value indicates the viability of the leaf and is associated with leaf gloss.

The most commonly used vegetation index for determining the health and stress of the plant is the Normalized Difference Vegetation Index (NDVI). NDVI is calculated using the red and near-infrared regions of the electromagnetic spectrum (Rouse et al., 1974; Tucker, 1979). In this study, NDVI values were calculated using the reflectance obtained with the spectroradiometer to investigate the stress level of rosemary plants (The formula for NDVI is given in Equation 3),

$$
N D V I=(N I R-R E D) /(N I R+R E D)
$$

In the equation, NIR refers to the near-infrared band and RED refers to the red band of the satellite images.

\subsection{Statistical analysis}

The obtained data were analyzed with analysis of variance (ANOVA). The differences between the groups according to the F-test results were determined by Duncan's Multiple Range Test (Açıkgöz and Açıkgöz, 2001).

\section{Results and Discussion}

According to the results of the first spectroradiometer measurement, as the amount of salt applied to the plant increased, the reflectance rate also increased in the near-infrared region. In the other regions of the electromagnetic spectrum, a proportional change was not observed depending on the salt level (Figure 3). In the following month, the reflectance of the plants increased in all regions of the electromagnetic spectrum due to salt stress, although this increase was not proportional to the amount of salt in all regions (Figure 4). The reflectance of the $23.04 \mathrm{~g}$ of salt applied to plants was observed to decrease in the second spectroradiometer measurement compared to the first one. Salt stress was found to increase the reflectance of the rosemary plants. According to the results of the second measurements, with the exception of the plants with the highest salt 


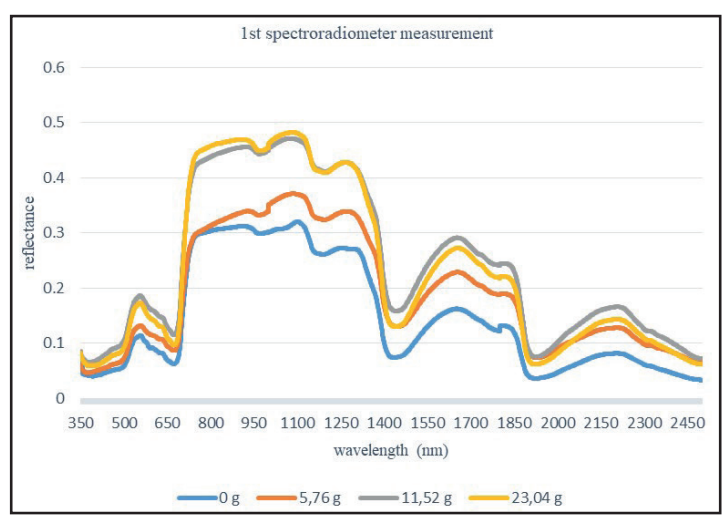

Figure 3. $1^{\text {st }}$ spectroradiometer measurement

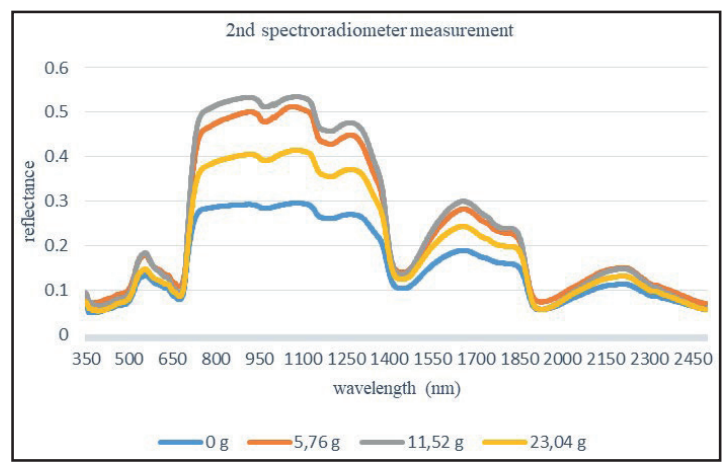

Figure 4. $2^{\text {nd }}$ spectroradiometer measurement

application $(23.04 \mathrm{~g})$, the reflectance of all the other plants continued to increase. In the plants applied with $23.04 \mathrm{~g}$ salt, the reflectance values decreased. The region with the biggest difference between reflectance values was near-infrared. In other studies where salt applications have been used on cucumber (Cucumis sativus L.) and wheat (Triticum aestivum L.), the region with the biggest difference between reflectance values was also near-infrared. This is due to near-infrared being the region where the plants show the most reflectivity (Yousef et al., 2011; Elmetwalli et al., 2012). In a salt study conducted with soybean plants (Glycine $\max$ L.), it was also observed that the reflectance of the plants applied with $\mathrm{NaCl}$ was higher than that of the control group in the near - infrared region. As the amount of salt applied to plants increased, their reflectance also increased. Spectroradiometer measurements in that study were made at the end of the second week (Krezhova and Kirova, 2011). In the current study, similar results were obtained in the first spectroradiometer measurements. According to the second measurement, however, the reflectance of plants applied with $23.04 \mathrm{~g}$ of salt decreased, which was attributed to the inability of these plants to tolerate that degree of salt stress.

The chlorophyll measurements were performed on the leaves of plants simultaneously with spectroradiometer measurements in order to observe the chlorophyll amount of plants depending on the stress level. The chlorophyll quantity in the leaf is one of the significant indicators used to measure photosynthesis speed and photosynthetic capacity in the plant (Yol and Uzun, 2011). In this study, although the salt application did not statistically change the chlorophyll content of the plants after both measurements, numerical differences have occurred (Table 1 and 2). According to obtained data, the maximum chlorophyll quantities were

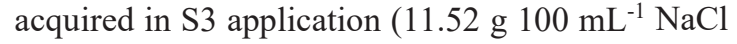
solutions for 4 weeks) with 2.300 and $\mathrm{S} 2$ application $\left(5.76 \mathrm{~g} 100 \mathrm{~mL}^{-1} \mathrm{NaCl}\right.$ solutions for 8

Table 1. Chlorophyll meter, spectroradiometer and spectrophotometer measurements after 4 weeks

\begin{tabular}{lccccc}
\hline $\begin{array}{l}\text { Salt concentrations } \\
\text { (gram in } 100 \mathrm{~mL}^{-1} \text { pure water) }\end{array}$ & $\mathrm{L}$ & Hue & Chroma & $\mathrm{K}$ & NDVI \\
\hline S1 & 45.48 & 157 & $16.60 \mathrm{~d}$ & 1.567 & 0.54 \\
S2 & 47.63 & 155 & $17.80 \mathrm{c}$ & 1.467 & 0.54 \\
S3 & 42.54 & 155 & $19.80 \mathrm{a}$ & 2.300 & 0.64 \\
S4 & 45.22 & 157 & $19.40 \mathrm{~b}$ & 1.267 & 0.64 \\
\hline F test & ns & ns & $* *$ & ns & ns \\
\hline
\end{tabular}

S1: 0 gram in $100 \mathrm{~mL}^{-1}$ pure water, S2: 5.76 gram in $100 \mathrm{~mL}^{-1}$ pure water, S3: 11.52 gram in $100 \mathrm{~mL}^{-1}$ pure water, $\mathrm{S} 4: 23.04$ gram in $100 \mathrm{~mL}^{-1}$ pure water, $\mathrm{L}$ : Represents the lustre of the leaf, Hue angle: The angle made by the $\mathrm{X}$-axis from the point where a and $\mathrm{b}$ values intersect, Chroma: Chroma value indicates the viability of the leaf and is associated with leaf gloss, K: Refers to the amount of chlorophyll in the leaf, NDVI: Normalised Difference Vegetation Index, ns: Not significant, $* *: p<0.01$

Table 2. Chlorophyll meter, spectroradiometer and spectrophotometer measurements after 8 weeks

\begin{tabular}{lccccc}
\hline $\begin{array}{l}\text { Salt concentrations } \\
\text { (gram in } 100 \mathrm{~mL}^{-1} \text { pure water) }\end{array}$ & $\mathrm{L}$ & Hue & Chroma & $\mathrm{K}$ & NDVI \\
\hline S1 & 46.67 & 167 & 20.50 & 1.633 & $0.51 \mathrm{c}$ \\
S2 & 44.51 & 161 & 19.40 & 3.700 & $0.58 \mathrm{~b}$ \\
S3 & 53.74 & 166 & 22.60 & 1.300 & $0.63 \mathrm{a}$ \\
S4 & 42.66 & 167 & 18.50 & 1.400 & $0.58 \mathrm{~b}$ \\
\hline F test & ns & ns & ns & ns & $* *$
\end{tabular}

ns: Not significant, $* *: \mathrm{p}<0.01$ 
weeks) with 3.700 . Until the 4th week, while salt stress does not decrease the chlorophyll ratio of the rosemary plant, as the stress application time increases, the chlorophyll ratio decreases (Table 1 and 2). Likewise, another researcher Tounekti et al. (2011) reported that rosemary plant (R. officinalis L.) tolerated salt stress for a certain period of time, but then pigment level decreased in increasing concentrations of $\mathrm{NaCl}$. The reactions formed in the plants against salt stress cause physiological changes controlled by complex molecular mechanisms, and when it continues, tolerance develops. The salt stress response can be species specific or can be similar within different taxa (Tiryaki, 2018). Orak and Ateş (2005) reported that the vetch plant (Vicia sativa L.) is not negatively affected by salt stress applied to the plant. However, Amira and Qados (2011) reported that as the salt rate applied to vetch increased, the amount of chlorophyll in the plant decreased.

In previous studies, color parameters of plants have been measured in order to determine their organic and inorganic substances, the quality, stress level, chlorophyll concentration, disease detection, leaf water potential, weed identification and, the maturity stage (Esti et al., 2002; Saranwong et al., 2004; Hernandez et al., 2007). In the current study, color parameters were used to evaluate the stress conditions of rosemary plants, and according to the data obtained, the most vivid color (intense green) was determined in the S3 and S4 applications, in the $4^{\text {th }}$ week (19.80 and 19.40, respectively). Although salt stress did not cause any statistically significant change in plant leaf color (chroma value), numeric value decreased in the $\mathrm{S} 4$ application in $8^{\text {th }}$ week (Table 1 and 2). As the stress application time and the applied salt rate increased, small changes in plant color occurred. Another researcher, investigating the physiological changes of rosemary plant ( $R$. officinalis L.) against salt stress, reported that there were changes in the plant as the stress duration and rate increased (Tounekti et al., 2011). They emphasized that rosemary plant can tolerate moderate doses of $\mathrm{NaCl}$. According to Qurie et al. (2019) rosemary plants have the ability to tolerate salinity. The L, a, $\mathrm{b}$ and chlorophyll meter measurement results may have been negatively affected due to the small leaves of rosemary plants. The minimum difference was observed in the leaf color of the plant and the plant was seen to easily adapt to the stress conditions. This adaptation is thought to be due to the small and fleshy leaf structure.

In addition, it was concluded that salt treatment increased the NDVI values of the plants (Figure 5 and 6). The NDVI values at the end of 4 weeks were observed to have increased in parallel with salt stress. The lowest values of the calculated NDVI indices were determined in the control group plants treated with pure water at the end of both the $4^{\text {th }}$ and $8^{\text {th }}$ weeks. According to the measurements made after 8 weeks, the NDVI values did not increase regularly based on the amount of salt applied. The reason for this may be that although the NDVI index is quite efficient for monitoring crops planted in large fields, it may not be very efficient in experiments with a small number of plants (Hernandez et al., 2014). The highest NDVI value was seen in the control group plants in another salt application study conducted on tomato plants (Solanum lycopersicum L.).

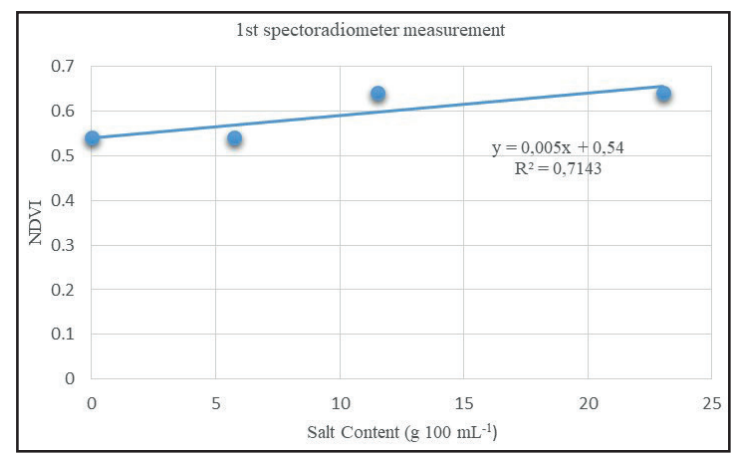

Figure 5. Relationship between NDVI and salt stress according to the $1^{\text {st }}$ spectroradiometer measurement

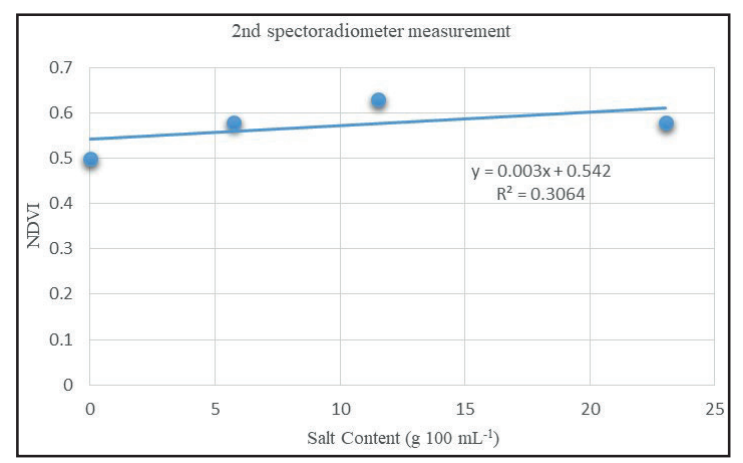

Figure 6. Relationship between NDVI and salt stress according to the $2^{\text {nd }}$ spectroradiometer

The lowest NDVI value was seen in plants treated with large amounts of salt. While the NDVI values were close to each other in different applications of salt in the first measurements, the values of the plants applied with salt decreased as the weeks progressed. This downtrend started from the $14^{\text {th }}$ week (Sönmez et al., 2015). The important issue here is the duration of the experiment. In studies where nitrogen fertilization has been applied, it has been found that NDVI value and chlorophyll content increases with fertilization. The reason for this is that the presence of nitrogen in the soil and chlorophyll in plants are directly related (Jones et al., 2007; Zhang et al., 2017). It has been reported that there is no correlation 
between NDVI values and chlorophyll amounts (Hernandez et al., 2014). Adding inorganic material such as salt to the plants could increase NDVI values but chlorophyll is not the only parameter affecting NDVI. In another study of salt application to melon plants (Cucumis melo L.), there was also observed to be no direct relationship between NDVI and chlorophyll content (Hernandez et al., 2014).

Remote sensing is a very effective method for determining the stress conditions of plants grown in a field environment. This can be accomplished using satellite imagery or a multispectral image from unmanned aerial vehicles. However, these methods cannot be used in a greenhouse environment because it is impossible to obtain satellite or multispectral images of plants grown in a greenhouse environment. Besides, satellite imagery and images obtained from unmanned aerial vehicles cannot be used directly to investigate plant stress. For this process, they need to be processed and classified which is a timeconsuming process (Gürsoy and Atun, 2019). The advantage of ground-based remote sensing is that it can provide direct data on the status of plants. It can also be easily applied to plants grown in greenhouses. Therefore, this methodology was applied to this study.

The environmental degradation and evaporation cause salinity, and water and soil salinity are serious challenges of sustainable agriculture. About 70 percent of available water, which is used for irrigation, is adding a considerable amount of salt to agricultural lands. For this reason, salt-tolerant plants are needed in these areas (Bernstein et al., 1993; Larcher, 1995; Tester and Davenport, 2003; Kalantari and Hassanli, 2012; Kalantari et al., 2018). Qurie et al. (2019) emphasize that rosemary plants have the ability to tolerate salinity. Moreover, they investigated the effect of irrigation with treated wastewater on this plant growth. As a result, they reported that there was no difference in plant growth compared to freshwater irrigation. According to the report of Kalantari et al. (2018) that despite the higher sodium concentration in the wastewater (16.99 meq $\left.\mathrm{L}^{-1}\right)$ compared to the freshwater $\left(9.15 \mathrm{meq} \mathrm{L}^{-1}\right)$, there was no statistically significant difference in sodium absorption by rosemary plants. It can be considered that the exposure of plants to different doses of salt with the same irrigation regime applied in this study may give different results depending on the structural properties of plants and salt stress tolerance in these plants.

\section{Conclusions}

This study was conducted to determine the effect of different salt concentrations on the reflectance values in the rosemary plant. LAB and chlorophyll measurements were also made on the leaves of the plants to support the spectral measurements. As a result of the study, the reactions of plants applied with salt were observed with the electromagnetic spectrum. The results were highlighting a significant relationship between salt stress and reflection values in the plant. The findings show that the reflectance values could be used to estimate the salt-stress level in plants.

\section{Acknowledgments}

This study was supported by CUBAP (Cumhuriyet University Scientific Research Projects) project numbered M-687.

\section{References}

Açıkgöz, A., Açıkgöz, N., 2001. Common mistakes in the statistical analyzes of agricultural experiments, I. Single factorials. Anadolu, J. of AARI, 11(1): 135147. (In Turkish).

Akram, F., Mahmood, F., Saifullah, M., Zafar, M., Saman, S. Yasmeen, S., Karamat, A., Tanveer, M.U., 2019. Identification of potential sites for rice plant growth using multi criteria decision (MCE) technique through remote sensing and GIS. International Journal of Agriculture and Sustainable Development, 1(4): 104-114.

Ali, R.R., Abd El Kader, A.A., Essa, E.F., AbdelRahman, M.A.E., 2019. Application of remote sensing to determine spatial changes in soil properties and wheat productivity under salinity stress. Plant Archives, 19(1): 616-621.

Allbed, A., Kumar, L., 2013. Soil salinity mapping and monitoring in arid and semi-arid regions using remote sensing technology: a review. Advances in Remote Sensing, 2(4): 373-385.

Amira, M.S., Qados A., 2011. Effect of salt stress on plant growth and metabolism of bean plant Vicia faba (L.). King Saud University Journal of the Saudi Society of Agricultural Sciences, 10: 7-15.

Argyrokastritis, I.G., Papastylianou, P.T., Alexandris, S., 2015. Leaf water potential and crop water stress index variation for full and deficit irrigation cotton in Mediterranean conditions. Agriculture and Agricultural Science Procedia, 4: 463-470.

Bayrak, A., 2006. Gida aromaları. Gida Teknolojisi Dergisi, 32: 268-273.

Bernstein, N., Lauchli, A., Silk, W.K., 1993. Kinematics and dynamics of sorghum (Sorghum bicolor L.) leaf development at various $\mathrm{Na} / \mathrm{Ca}$ salinities (I. Elongation growth). Plant Physiology, 103(3): 11071114. 
Birdal, A.C, Avdan, U., Türk, T., 2017. Estimating tree heights with images from an unmanned aerial vehicle. Geomatics, Natural Hazards and Risk, 8(2): 1144-1156.

Caturegli, L., Grossi, N., Saltari, M., Gaetani, M., Magni, S., Nikolopoulou, A.E., Bonari, E., Volterrani, M., 2015. Spectral reflectance of tall fescue (Festuca arundinacea Schreb.) under different irrigation and nitrogen conditions. Agriculture and Agricultural Science Procedia, 4: 59-67.

Chemura, A., Mutanga, O., Dube, T., 2017. Remote sensing leaf water stress in coffee (Coffea arabica) using secondary effects of water absorption and random forest. Physics and Chemistry of the Earth, 30(100): 1-8.

Cordell, S., Questad, E.J., Asner, G.P., Kinney, K.M., Thaxton, J.M., Uowolo, A., Brooks, S., Chynoweth, M.W., 2017. Remote sensing for restoration planning: how the big picture can inform stakeholders. Restoration Ecology, 25(S2): 147-154.

Çamoğlu, G., Genç, L., 2013. Use of thermal imaging and spectral data to detect water stress in green bean. COMU Journal of Agriculture Faculty, 1(1): 15-27. (In Turkish).

Çulha, Ş., Çakırlar, H., 2011. The effect of salinity on plants and salt tolerance mechanisms. Afyon Kocatepe University Journal of Sciences, 11(2): 1134. (In Turkish).

Elmetwalli, A.M.H., Tyler, A.N., Hunter, P.D., Salt, C.A., 2012. Detecting and distinguishing moistureand salinity-induced stress in wheat and maize through in situ spectroradiometry measurements. Remote Sensing Letters, 3(5): 363-372.

Esti, M., Cinquanta, L., Sinesio, F., Moneta, E., Di Matteo, M., 2002. Physicochemical and sensory fruit characteristics of two sweet cherry cultivars after cool storage. Food Chemistry, 76(4): 399-405.

Freed, R.D., Eisensmith, S.P., Everson, E.H., Weber M., Paul, E., Isleib, D., 1988. MSTAT-C, A Microcomputer Program for the Design, Management and Analysis of Agronomic Research Experiments. Michigan State University Institute of International Agriculture, East Lansing, USA.

Gürsoy, Ö., Atun, R., 2019. Using remote sensing in detecting sugar beet fields treated with different doses of phosphorus. Fresenius Environmental Bulletin, 28(2A): 1247-1253.

Gürsoy, Ö., Canbaz, O., Gökçe, A., Atun, R., 2017. Spectral classification in lithological mapping: A case study of matched filtering. Cumhuriyet Science Journal, 38(4): 731-737.

Hatchell, D.C., 1999. Analytical Spectral Devices, Inc. (ASD) Technical Guide. Boulder, USA.

He, L., Zhang, H.Y., Zhang, Y.S., Song, X., Feng, W., Kang, G.Z., Wang, C.Y., Guo, T.C., 2016. Estimation canopy leaf nitrogen concentration in winter wheat based on multiangular hyperspectral remote sensing. European Journal of Agronomy, 73: 170-185.
Hernandez, H.I., Pastor, I.M., Pedreno, J.N., Gomez, I., 2014. Spectral indices for the detection of salinity effects in melon plants. Scientia Agricola, 71(4): 324-330.

Hernandez, M., Rodriguez, E., Diaz, C., 2007. Free hydroxycinnamic acids, lycopene, and color parameters in tomato cultivars. Journal of Agricultural Food Chemistry, 55(21): 8604-8615.

Jones, C.L., Weckler, P.R., Maness, N.O., Jayasekara, R., Stone, M.R., Chrz, D., 2007. Remote sensing to estimate chlorophyll concentration in spinach using multi-spectral plant reflectance. American Society of Agricultural and Biological Engineers, 50(6): 22672273.

Kalantari, E., Hassanli, A.M., 2012. Arid and semi-arid lands management assessment using biological recovery methods and the use of unconventional water. The First National Conference on Strategies for Achieving Sustainable Development in Agriculture, Natural Resources and the Environment, 10-11 March, Tehran, Iran.

Kalantari, E., Hassanli, A.M., Ghanbarian, G.A., Ghaemi, A.A., Mousavi, S.R., 2018. Local desalination treatment plant wastewater reuse and evaluation potential absorption of salts by the halophyte plants. Eurasian Journal of Soil Science, 7(1): 43-50.

Katsoulas, N., Elvanidi, A., Ferentinos, K.P., Kacira, M., Bartzanas, T., Kittas, C., 2016. Crop reflectance monitoring as a tool for water stress detection in greenhouses: A review. Biosystems Engineering, 151: 374-398.

Kırp1k, M., 2005. Researches on the yield and quality of rosemary (Rosmarinus officinalis L.) cultivars grown in dryland and highland conditions of Çukurova region. $\mathrm{PhD}$ thesis, University of Çukurova, Institute of Natural and Applied Sciences, Adana. (In Turkish).

Krezhova, D., Kirova, E., 2011. Hyperspectral remote sensing of the impact of environmental stress on nitrogen fixing soybean plants (Glycine max L.). Proceedings of $5^{\text {th }}$ International Conference on Recent Advances in Space Technologies, 9-11 June, Turkey, pp. 172-177.

Larcher, W., 1995. Physiological Plant Ecology: Ecophysiology and Stress Physiology of Functional Groups. Springer-Verlag, New York.

Lemos, M.F., Pacheco, H.P., Endringer, D.C., Scherer, R., 2015. Seasonality modifies rosemary's composition and biological activity. Industrial Crops and Products, 70: 41-47.

Lugassi, R., Goldshleger N., Chudnovsky A., 2017. Studying vegetation salinity: from the field view to a satellite-based perspective. Remote Sensing, 122(9): $1-16$.

Mac Arthur, A.A., Maclellan, C., Malthus, T.C., 2007. Determining the FOV and directional response of field spectroradiometers. $5^{\text {th }}$ EARSeL Workshop on Imaging Spectroscopy, Proceedings, April 23-25, Bruges, s. 1-8. 
McGuire, R.G., 1992. Reporting of objective color measurements. American Society for Horticultural Science, 27(12): 1254-1255.

Meggio, F., Zarco-Tejada, P.J., Nunez, L.C., SepulcreCanto, G., Gonzalez, M.R., Martin, P., 2010. Grape quality assessment in vineyards affected by iron deficiency chlorosis using narrow-band physiology remote sensing indices. Remote Sensing of Environment, 114(9): 1968-1986.

Olmedo, R.H., Nepote, V., Grosso, N.R., 2013. Preservation of sensory and chemical properties in flavoured cheese prepared with cream cheese base using oregano and rosemary essential oils. Lwt-Food Science Techology, 53(2): 409-417.

Orak, A., Ateș E., 2005. Resistance to salinity stress and available water levels at the seedling stage of the common vetch (Vicia sativa L.). Plant Soil and Environment, 51: 51-56.

Özyiğit, Y., 2017. An estimation of some plant traits with the remote sensing method in the narbon bean (Vicia narbonensis L.). Fresenius Environmental Bulletin, 26(10): 6043-6048.

Özyiğit, Y., Bilgen, M., 2013. Use of spectral reflectance values for determining nitrogen, phosphorus and potassium contents of rangeland plants. Journal of Agricultural Science and Technology, 15(7): 1537-1545.

Parry, C., Blonquis, J.M., Bugbee, B., 2014. In situ measurement of lead chlorophyll concentration: analysis of the optical/absolute relationship. Plant Cell and Environment, 37(11): 2508-2520.

Pinter, P.J., Hatfield, J.L., Schepers, J.S., Barnes, E.M., Moran, M.S., Daughtry, C.S.T., Upchurch, D.R., 2003. Remote sensing for crop management. Photogrammetric Engineering and Remote Sensing, 69(6): 647-664.

Qurie, M., Daghra, S., Khamis, M., Kanan, A., Barghouthi, Z., Alimari, A., Nussiebah S., Karaman, R., 2019. Rosemary (Rosmarinus officinalis) plants irrigation with secondary treated effluents using epuvalisation technology. Net Journal of Agricultural Science, 7(2): 69-77.

Ramoelo, A., Dzikiti, S., Deventer, H.V., Maherry, A., Cho, M.A., Gush, M., 2015. Potential to monitor plant stress using remote sensing tools. Journal of Arid Environments, 113: 134-144.

Rouse, J.W., Haas, R.H., Schell, J.A., Deering, D.W., 1974. Monitoring vegetation systems in the great plains with ERTS. Third ERTS-1 Goddard Space Flight Center 3d ERTS-1, Paper A20, 01 January, Washington DC, pp. 309-317.

Saranwong, S., Sornsrivichai, J., Kawano, S., 2004. Prediction of ripe-stage eating quality of mango fruit from its harvest quality measured nondestructively by near infrared spectroscopy. Postharvest Biology and Technology, 31(2): 137-145.

Simon, J.E., Chadwick A.F., Craker, L.E., 1984. Herbs: An Indexed Bibliography. 1971-1980 the Scientific Literature on Selected Herbs, and Aromatic and Medicinal Plants of the Temperate Zone. Archon Books, Hamden.
Sönmez, N.K., Aslan, G.E., Kurunç, A., 2015. Relationship spectral reflectance under different salt stress conditions of tomato. Journal of Agricultural Sciences, 21(4): 585-595. (In Turkish).

Sytar, O., Brestic, M., Zivcak, M., Olsovska, K., Kovar, M., Shao, H., He, X., 2017. Applying hyperspectral imaging to explore natural plant diversity towards improving salt stress tolerance. Science of the Total Environment, 578: 90-99.

Tester, M., Davenport, R., 2003. Na tolerance and Na transport in Higher plants. Annals of Botany, 91(5): 503-527.

Tilling, A.K., O'leary, G.J., Ferwerda, J.G., Jones, S.D., Fitzgerald, G.J., Rodriguez, D., Belford, R., 2007. Remote sensing of nitrogen and water stress in wheat. Field Crops Research, 1(3): 77-85.

Tiryaki, İ., 2018. Adaptation mechanisms of some field plants against to salt stress. Kahramanmaraş Sütçü Imam University Journal of Agriculture and Nature, 21(5): 800-808. (In Turkish).

Tounekti, T., Vadel, A.M., Onate, M., Khemira, H., Munné-Bosch, S., 2011. Salt-induced oxidative stress in rosemary plants: Damage or protection. Environmental and Experimental Botany, 71: 298305.

Trigueros, C.R., Nortes, P.A., Alarcon, J.J., Hunink, J.E., Parra, M., Contreras, S., Droogers, P., Nicolas, E., 2017. Effects of saline reclaimed waters and deficit irrigation on Citrus physiology assessed by UAV remote sensing. Agricultural Water Management, 183: 60-69.

Tucker, C.J., 1979. Red and photographic infrared linear combinations for monitoring vegetation. Remote Sensing of Environment, 8(2): 127-150.

Yol, E., Uzun, B., 2011. Inheritance of number of capsules per leaf axil and hairiness on stem, leaf and capsule of sesame (Sesamum indicum L.). Agricultural Journal of Crop Science, 5(1): 78-81.

Yousef, S., Summy, K.R., Little, C.R., 2011. Detection of salt toxicity and nitrogen deficiency in Cucumis sativus L. using spectroradiometry and color infrared imagery. Journal of Plant Nutrition, 34: 1236-1244.

Yousfi, S., Kellas, N., Saidi, L., Benlakehal, Z., Chaou, L., Siad, D., Herda, F., Karrou, M., Vergara, O., Gracia, A., Araus, J.L., Serret, M.D., 2016. Comparative performance of remote sensing methods in assessing wheat performance under Mediterranean conditions. Agricultural Water Management, 164(1): 137-147.

Wang, L., Zhou, X., Zhu, X., Guo, W., 2017. Estimation of leaf nitrogen concentration in wheat using the MK-SVR algorithm and satellite remote sensing data. Computers and Electronics in Agriculture, 140: 327-337.

Zhang, K., Ge, X., Liu, X., Zhang, Z., Liang, Y., Tian, Y., Cao, Q., Cao, W., Zhu, Y., Liu, X., 2017. Evaluation of the chlorophyll meter and GreenSeeker for the assessment of rice nitrogen status. Advances in Animal Biosciences: Precision Agriculture, 8(2): 1-5. 